\title{
TIDAK SEDERHANA MEWUJUDKAN INDUSTRI PENGOLAHAN NIKEL LATERIT KADAR RENDAH DI INDONESIA SEHUBUNGAN DENGAN UNDANG- UNDANG MINERBA 2009
}

\author{
No Simple to Realize Low Grade Laterite Nickel Processing Industry \\ in Connection with Indonesian Mining Law 2009
}

\author{
PUGUH PRASETIYO \\ Puslit Metalurgi dan Material (P2M2) LIPI \\ Kawasan PUSPIPTEK Gedung 470, Cisauk, Tangerang Selatan \\ Banten 15314, Indonesia \\ Telp. +62 217560911, Fax. +62 217560553 \\ e-mail: pprasetiyo2002@yahoo.com
}

\begin{abstract}
ABSTRAK
Ada dua jalur proses untuk mengolah bijih nikel oksida yang lazim disebut laterit, yaitu pirometalurgi dan hidrometalurgi. Pirometalurgi digunakan untuk mengolah laterit jenis saprolit berkadar nikel tinggi $(\mathrm{Ni} \geq 1,8 \%)$ untuk memproduksi $\mathrm{FeNi}$ atau $\mathrm{Ni}$ matte. Hidrometalurgi digunakan untuk mengolah laterit kadar rendah $(\mathrm{Ni}<1,8 \%)$ yang belum ada di tanah air. Dalam perkembangannya pirometalurgi digunakan untuk mengolah laterit kadar rendah menghasilkan NCPI/NPI (Nickel Contain Pig Iron/Nickel Pig Iron) di Tiongkok. Selanjutnya $\mathrm{NCPI} / \mathrm{NPI}$ digunakan sendiri oleh Tiongkok sebagai pengganti FeNi untuk membuat besi-baja tahan karat. Bahan baku pembuatan NCPI/NPI Tiongkok diperoleh dari mengimpor laterit Filipina dan Indonesia. Dengan mulai berlakunya UU Minerba (Mineral dan Batubara) tahun 2009 yang mewajibkan bahan baku harus diolah di dalam negeri sebelum diekspor, dan melarang ekspor bahan baku mulai 12 Januari 2014. Maka Indonesia mungkin akan menghadapi masalah hukum dagang internasional yang tidak sederhana sebagai konsekuensi dari larangan ekspor mineral. Masalah lainnya bagaimana harus mengolah mineral di dalam negeri, dan siapa yang akan menyerap pasar hasil olahan mineral. Melihat kenyataan ini pemerintah harus mengoptimalkan litbang (penelitian dan pengembangan) yang ada di departemen maupun non departemen.
\end{abstract}

Kata kunci : laterit kadar rendah, limonit, saprolit, pyrometalurgi, hydrometalurgi, UU. Minerba 2009.

\begin{abstract}
There are two process lines in beneficiating nickel oxide ores or lateritic ore by using the pyrometallurgy and hydrometallurgy. The pyrometallurgy technology has been applied to process saprolite containing high grade nickel laterite ( $\mathrm{Ni} \geq 1.8 \%$ ) to produce FeNi or Ni matte. While, the hydrometallurgy technology has been applied to process low grade laterite $(\mathrm{Ni}<1.8 \%)$, however, the last type of the process is not applied yet in Indonesia. Based on technology development, the pyrometallurgy has been used successfuly to process low-grade laterite for NCPI / NPI (Nickel ContainPig Iron / Nickel Pig Iron) production in China, which is subsequently utilized solely by the Chinese as a substituted FeNi in stainless steel making. The raw material for manufacturing NCPI / $\mathrm{NPI}$, China has imported laterite ore from the Philippines and Indonesia. Presently, with the issuance of the Mining Law of mineral and coal in 2009, which requires that raw materials must be processed within the country before being exported, and have prohibited the export of raw materials since January, 12, 2014. Hence, Indonesia might be facing the problem of international commercial law in the future, which would not be a simple consequence of the ban of exporting raw minerals. Another problem is how to process the mineral in the
\end{abstract}


country, and who will be the market customer target of the processed minerals. Due to this reality, the Indonesian government must optimize the research and development that has been done by many departments or non-departmental institutions.

Key words: the low grade laterite, limonite, saprolite, pyrometallurgy, hydrometallurgy, mining law 2009.

\section{PENDAHULUAN}

Undang-Undang Mineral dan Batubara (UU Minerba) tahun 2009, melarang ekspor bahan baku mineral, semua mineral mentah harus diolah di dalam negeri sebelum diekspor. Mulai 12 Januari 2014, ekspor mineral dihentikan dan wajib untuk mengolah mineral di dalam negeri. Indonesia sebagai negara yang berlimpah dengan sumber daya alam bijih nikel oksida yang lazim disebut laterit, akan menghadapi masalah yang tidak sederhana sehubungan dengan terbitnya UU Minerba tersebut. Indonesia mungkin akan menghadapi masalah hukum dagang internasional yang tidak sederhana sebagai konsekuensi dari larangan ekspor mineral. Sedangkan untuk mewujudkan industri pengolahan laterit baik terhadap bijih kadar tinggi maupun kadar rendah, selain dibutuhkan dana yang tidak sedikit dan teknologi yang sesuai, juga siapa target pasar yang siap menyerap produk hasil olahan tersebut. Oleh karena itu, yang bisa mewujudkan industri pengolahan laterit adalah BUMN seperti PT Aneka Tambang atau PMA seperti PT Vale Indonesia, dan untuk bisa terwujud sangat dibutuhkan kepedulian pemerintah.

Laterit jenis saprolit yang berkadar nikel tinggi $(\mathrm{Ni} \geq 1,8 \%$ memang tidak ada masalah dengan terbitnya UU Minerba, karena tipe saprolit tersebut sudah diolah di Pomalaa, Sulawesi Tenggara untuk memproduksi FeNi (ferro nikel) oleh BUMN PT Antam (Aneka Tambang), dan untuk memproduksi nikel matte (Ni-Matte) di Sorowako oleh PMA yaitu PT Vale Indonesia. Namun sebaliknya untuk bijih laterit kadar rendah yang terdiri dari limonit dan saprolit yang memiliki kandungan $\mathrm{Ni}<1,8 \%$, otomatis akan menjadi masalah yang tidak sederhana. Karena untuk mewujudkan industri pengolahan laterit kadar rendah selain dibutuhkan dana yang tidak sedikit dan teknologi yang sesuai, juga perlu pasar yang siap menyerap produk hasil olahan.

Dengan terbitnya UU Minerba maka otomatis juga akan berpengaruh pada ekspor bijih nikel laterit oleh BUMN (PT Antam). Karena laterit kadar tinggi jenis saprolit dari Pomalaa sudah diekspor ke Jepang sejak era pemerintah kolonial Belanda. Pada era kolonial Belanda mulai tahun 1930-an, ekspor dilakukan oleh Oost Borneo Maatschappy (OBM) perusahaan milik pemerintah kolonial. Selain ke Jepang, ekspor laterit oleh PT Antam juga dilakukan ke Australia untuk limonit dengan persyaratan tertentu, dan juga ke Tiongkok untuk saprolit kadar rendah dengan kandungan $\mathrm{Ni} \geq 1,5 \%$. (Wiryokusumo, Loebis, et al. 1997; Anonim, 1999; Jiang, Wang, et al. 2014).

Adapun pembahasan terhadap laterit kadar rendah ini bertujuan untuk memberi pencerahan, memberi informasi perkembangan industri dan teknologi pengolahan laterit kadar rendah di beberapa negara termasuk di Indonesia, sehingga menggugah para penentu kebijakan mineral Indonesia, mau diapakan laterit kadar rendah yang terdiri dari limonit dan saprolit yang mengandung $\mathrm{Ni}<1,8 \%$ dan belum bisa diolah di Indonesia. Karena laterit adalah kekayaan alam Indonesia yang jumlahnya berlimpah. Jika bukan kita yang peduli dengan kekayaan alam ini, siapa lagi yang harus peduli.

\section{METODE}

Kajian ini dilakukan berdasarkan data sekunder dari berbagai referensi, data-data dikumpulkan, dikompilasi dan disusun mulai dari inventarisasi proses-proses pengolahan laterit kadar rendah, perkembangan teknologi pemrosesan bijih nikel laterit, kondisi pertambangan nikel laterit di Indonesia dan keterkaitannya dengan Undang Undang Minerba 2009.

\section{PEMBAHASAN}

\section{Inventarisasi Proses Pengolahan Laterit Kadar Rendah}

Secara ideal endapan laterit dialam dari daerah tropis dan proses pengolahannya, dapat dilihat pada Gambar 1. 


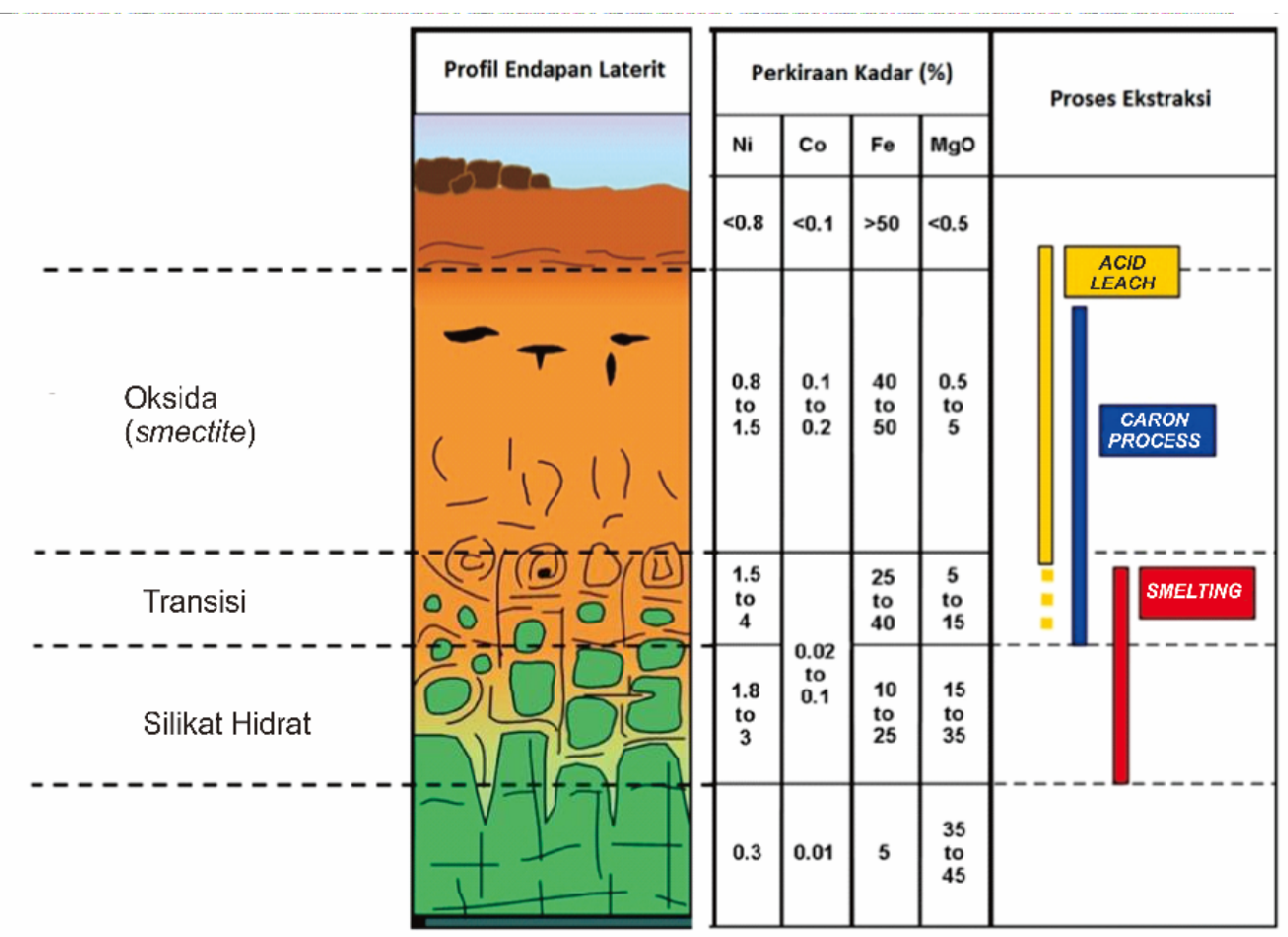

Gambar 1. Lapisan ideal laterit daerah tropis dialam dan pengolahannya (Butt,2007)

Ada dua jalur proses pengolahan laterit untuk memasok kebutuhan nikel dunia, yaitu pirometalurgi dan hidrometalurgi. Adapun diagram alir proses pengolahan laterit yang sudah komersial dengan jalur pirometalurgi dan hidrometalurgi, dapat dilihat pada Gambar 2.

Pirometalurgi digunakan untuk mengolah saprolit berkadar nikel tinggi $(\mathrm{Ni} \geq 1,8 \%$ di Indonesia) untuk memproduksi FeNi seperti produksi PT Aneka Tambang di Pomalaa, Sulawesi Tenggara. Atau untuk memproduksi Ni-matte seperti produksi PT Vale Indonesia di Sorowako, Sulawesi Tenggara. Secara global sebagian besar proses pirometalurgi digunakan untuk memproduksi FeNi. (Dalvi, Bacon., et al. 2004). Selanjutnya FeNi digunakan untuk membuat baja tahan karat atau stainless steel (SS).

Hidrometalurgi digunakan untuk mengolah laterit kadar rendah yang terdiri dari limonit dan saprolit kadar rendah dengan kandungan $\mathrm{Ni}<1,8 \%$ (di Indonesia). Pada umumnya proses Caron digunakan untuk mengolah serpentin (saprolit kadar rendah) guna memproduksi $\mathrm{NiO}$ (nickel oxide). Sedangkan proses HPAL/PAL (High Pressure Acid
Leaching/ Pressure Acid Leaching) untuk mengolah limonit guna memproduksi $\mathrm{NiS}$ (nickel sulfide). Di Indonesia belum ada pabrik pengolahan laterit kadar rendah menggunakan teknologi hidrometalurgi, baru hanya sebatas ijin dari pemerintah kepada pihak asing. PT Pasific Níkel USA mendapat ijin untuk mengolah laterit pulau Gag Papua dengan proses Caron pada Februari tahun 1969. (Anonim, 2012). Perkembangan selanjutnya PT Pasific Níkel USA mengembalikan ijin ke pemerintah. Kemudian pada Februari 1998, pemerintah memberi ijin lagi untuk mengolah laterit dengan proses berbasis HPAL/PAL kepada dua PMA yaitu PT BHP Australia untuk mengolah laterit pulau Gag Papua, dan PT Weda Bay Níkel (WBN) Canada untuk mengolah laterit teluk Weda Halmahera Maluku Utara, dimana ijin yang dikeluarkan oleh pemerintah pada Febuari 1998 adalah kontrak karya (kk) generasi ke 7 (www.gagnickel.com., Baillie, 2002).

Adapun pionir pengolahan laterit kadar rendah dengan jalur hidrometalurgi adalah Freeport USA yang beroperasi di Cuba sampai 1960. Pabrik untuk mengolah laterit kadar rendah jenis serpentin (saprolit kadar rendah) dengan proses Caron untuk memproduksi 
$\mathrm{NiO}$ dibangun di Nicaro, Cuba pada tahun 1942/1943. Freeport USA dengan bantuan Sherrit Gordon Canada juga membangun pabrik untuk mengolah limonit dengan proses HPAL/PAL untuk memproduksi NiS di Moa Bay tahun 1959. Perkembangan selanjutnya, Freeport USA dinasionalisasi oleh pemerintah Cuba dibawah rezim Fidel Castro pada 1960. Sampai saat ini (2015) kedua pabrik tersebut masih beroperasi, dan di Punta Gorda Cuba beroperasi pabrik untuk mengolah laterit kadar rendah jenis serpentin dengan proses Caron yang mulai beroperasi 1986 (Habashi, 1993). Diluar Cuba kedua proses tersebut (proses Caron dan proses HPAL/PAL) digunakan untuk mengolah laterit kadar rendah seperti di Australia, New Caledonia, Papua Nugini, Philipina, Brasilia, dan pulau Madagaskar Afrika. Pada era tahun 2000-an pasca kegagalan tiga HPAL/PAL plant generasi kedua di Australia, pengolahan laterit kadar rendah beralih pada pembuatan NCPI/NPI untuk memproduksi besi-baja yang dipelopori oleh Tiongkok. Adapun dasar pemilihan proses untuk mengolah laterit berdasarkan biaya modal (Capex) dan biaya operasi (Opex) untuk memproduksi FeNi, NPI, dan menggunakan proses HPAL/PAL, dapat dilihat pada Tabel 1.

Biaya modal (Capex) membuat NPI di Tiongkok lebih murah karena Tiongkok tidak perlu membangun pabrik baru untuk memproduksi NPI. Pabrik-pabrik peleburan besi/baja yang sudah ada yang tadinya untuk memproduksi besi-baja "dimodifikasi" untuk memproduksi NPI. Seluruh produk NPI dibeli oleh pemerintah Tiongkok digunakan untuk membuat besi-baja. Biaya operasi (Opex) pembuatan NPI relatif mahal dibandingkan dengan HPAL/PAL dan FeNi. Biaya operasi (Opex) tersebut tidak menjadi masalah karena Cina mempunyai energi listrik yang berlimpah dari PLTA Tiga Ngarai bendungan terbesar di dunia. Bahkan pemerintah mengeluarkan kebijakan agar pabrik-pabrik yang menggunakan blast furnace (BF), secara bertahap supaya beralih menggunakan rotary kiln (RK) dan electric furnace (EF) yang lebih ramah terhadap lingkungan. Karena pemakaian batubara pada blast furnace (BF) tidak ramah terhadap lingkungan. (Lennon, 2007).



Gambar 2. Diagram alir proses pengolahan laterit (Rodrigues, 2013) 
Tabel 1. Modal dan biaya operasi untuk memproduksi FeNi, NPI, dan menggunakan proses HPAL/PAL (Elias, 2013)

\begin{tabular}{lcc}
\hline \multicolumn{1}{c}{ Produk/Proses } & $\begin{array}{c}\text { Biaya Modal } \\
\text { (US \$/lb Ni tahun) }\end{array}$ & Biaya Operasi \\
\hline FeNi & $30-40$ & Pertengahan \\
NPI (BF : Blast Furnace) & $10-15$ & Tinggi \\
HPAL & $30-40$ & Pertengahan \\
\hline
\end{tabular}

\section{Proses Caron}

Proses Caron telah digunakan di beberapa negara seperti yang ditunjukkan pada Tabel 2 .

Proses Caron tergolong sebagai kombinasi jalur piro-hidrometalurgi karena melalui tahapan pengeringan yang dilanjutkan dengan kalsinasi/reduksi pada suhu $\pm 760{ }^{\circ} \mathrm{C}$, dan terhadap produk kalsinasi/reduksi dilakukan pelindian dengan pelarut AAC (Ammonia Ammonium Carbonate) pada temperatur kamar dan tekanan atmosfir. Secara teknologi proses Caron sudah mapan (proven) namun proses ini mulai ditinggalkan sebagai akibat kenaikan harga minyak dunia yang dramatis setelah 1973. Sehingga bagi perusahaan perusahaan yang tidak mampu menyiasati harga BBM (Bahan Bakar Minyak) yang mahal agar tetap beroperasi, terpaksa tutup seperti yang ditunjukkan pada Tabel 2. Perusahaan yang berencana akan membangun pabrik baru seperti PT Pasific Níkel USA, terpaksa batal membangun pabrik di pulau Gag Papua Indonesia pada 1974. Akhirnya menurut informasi www.gagnickel.com bahwa PT Pasific Níkel USA mengembalikan ijinnya ke pemerintah Indonesia. Akibat harga BBM yang mahal maka pemain nikel dunia melakukan litbang (penelitian dan pengembangan) proses pengolahan laterit dengan proses HPAL/PAL. Karena proses HPAL/PAL telah terbukti di Moa Bay plant Cuba mengkonsumsi energi rendah dengan perolehan yang tinggi baik untuk nikel maupun kobal yaitu $\mathrm{Ni}>90 \%$ dan $\mathrm{Co}>90 \%$.

\section{Proses HPAL/PAL}

Prinsip proses HPAL/PAL, dimulai dengan cara limonit dilindi menggunakan asam sulfat $\left(\mathrm{H}_{2} \mathrm{SO}_{4}\right)$ pada temperatur $\left(230-260{ }^{\circ} \mathrm{C}\right)$ dan bertekanan tinggi $(4000-4500 \mathrm{kPa})$ di dalam autoclave. HPAL/PAL plant generasi pertama dibangun di Moa Bay oleh Freeport USA dengan bantuan Sherrit Gordon Canada pada tahun 1958/1959. Moa Bay plant belum selesai pembangunannya saat pemerintah Cuba (dibawah rezim Fidel Castro) menasionalisasi Freeport tahun 1960. Dengan bantuan Uni Soviet (Rusia) maka proyek tersebut bisa dirampungkan pada tahun 1961. Moa Bay plant baru bisa berjalan dengan normal setelah mengalami berbagai ragam kesulitan dalam kurun waktu 7 tahun. Seiring dengan bubarnya Uni Soviet (Rusia) pada tahun 1990an, membawa pengaruh terhadap Moa Bay plant karena selama ini semua produk NiS dibeli oleh Uni Soviet (Rusia). Melihat kenyataan ini maka pemerintah Cuba melakukan kerja sama dengan Sherrit Gordon Canada untuk proyek Moa Bay (dengan kepemilikan sama masing masing $50 \%$ ) yang ditanda tangani Desember 1994. Dalam perjanjian kerja sama tersebut kinerja Moa Bay plant diperbaiki dari penambangan sampai pengolahan, dan seluruh produk NiS diolah lebih lanjut oleh Sherrit Gordon di Fortsaskatchewan Canada. (Chalkley, Toirac, 1997).

Tabel 2. Negara-negara pengguna proses Caron (Prado, 2014)

\begin{tabular}{llcc}
\hline \multicolumn{1}{c}{ Perusahaan } & \multicolumn{1}{c}{ Lokasi } & Tahun Beroperasi & Status \\
\hline Cubaniquel & Nicaro, Holguin, Cuba & 1945 & Beroperasi \\
QNY & Yabulu, Australia & 1974 & Beroperasi \\
Niquel Tocantins & Niquelandia, Brazil & 1981 & Beroperasi \\
Cubaniquel & Punta Gorda, Cuba & 1986 & Beroperasi \\
Ferromin & Sered, Slovakia & 1958 & Tutup \\
International Níkel & Sudbury, Canada & 1975 & Tutup \\
Nonoc & Philipina & 1975 & Tutup \\
\hline
\end{tabular}


Berkat kerja sama tersebut terjadi perbaikan yang cukup berarti terhadap produksi NiS. Dari kapasitas pabrik \pm 25.000 ton Ni/tahun, berturut-turut dicapai produksi tertinggi \pm 19.500 ton Ni/tahun pada tahun 1989, selanjutnya produksi bisa ditingkatkan menjadi \pm 20.651 ton $\mathrm{Ni} /$ tahun pada tahun 1995 dan meningkat lagi menjadi \pm 26.035 ton $\mathrm{Ni} /$ tahun pada tahun 1996 . Telah terbukti pula bahwa sampai mendapatkan produk akhir NiS ternyata berbiaya operasi murah, yaitu US \$ 3.12/lb Ni (Chalkley, Toirac, 1997.; Wedderburn, 2010).

Kesuksesan Moa Bay HPAL plant menjadikan proses HPAL sebagai pilihan utama untuk mengolah laterit kadar rendah kedepan, untuk memenuhi kebutuhan nikel dunia yang terus meningkat terutama nikel untuk bahan baku besi-baja tahan karat (SS : stainless steel). Disamping itu cadangan laterit secara global $\pm 70 \%$ berupa limonit yang merupakan laterit kadar rendah seperti yang ditunjukkan pada Tabel 3.

Tabel 3. Cadangan laterit secara global (Elias, 2013)

\begin{tabular}{ccccc}
\hline & $\begin{array}{c}\text { Milyar } \\
\text { ton } \\
\text { bijih }\end{array}$ & $\% \mathrm{Ni}$ & $\begin{array}{c}\text { Milyar } \\
\text { ton } \\
\text { logam } \\
\mathrm{Ni}\end{array}$ & $\begin{array}{c}\% \\
\text { Total }\end{array}$ \\
\hline $\begin{array}{c}\text { Saprolit } \\
\text { (silikat) }\end{array}$ & 2700 & 1,79 & 48 & 30 \\
Limonit & 9600 & 1,17 & 112 & 70 \\
Total & 12.300 & & 160 & 100 \\
\hline
\end{tabular}

Disamping sukses Moa Bay HPAL/PAL plant juga ada litbang (penelitian dan pengembangan) lain yang sukses untuk proses HPAL, dan modifikasi proses berbasis HPAL. Litbang yang sukses dilakukan oleh Sherrit Gordon Canada terutama untuk proses HPAL, AMAX USA terutama untuk modifikasi proses berbasis HPAL, COFREMMI Perancis, dan kerja sama AMAX-COFREMMI untuk pilot plant skala besar untuk mengolah laterit dari New Caledonia dengan proses berbasis HPAL yang dimodifikasi. (Wicker and Jha, 1986.; Anonim, 1986).

Selanjutnya bermunculan rencana untuk membangun pabrik pengolahan laterit kadar rendah dengan HPAL oleh pemain nikel dunia di Australia, Philipina, Indonesia, Papua Nugini, Kaledonia Baru, Madagaskar, Brasilia, dsb. Namun yang terealisasi sampai 2004 hanya lima (5) HPAL plant, dan hal ini dapat dilihat pada Tabel 4.

Walaupun teknologi HPAL telah sukses pada skala laboratorium maupun skala pilot plant untuk mengolah berbagai jenis laterit. Kenyataan yang terjadi, teknologi HPAL gagal saat digunakan pada tiga HPAL plant generasi kedua di Australia.Tiga HPAL plant generasi kedua tersebut adalah Bulong, Cawse, dan Murrin-Murrin. Akhirnya Bulong tutup pada tahun 2003, Cawse mengikuti jejak Bulong tutup pada tahun 2008. Sedangkan MurrinMurrin berpindah kepemilikan ke Minara pada tahun 2004, selanjutnya Minara mengolah sebagian laterit kadar rendah dengan heap leaching $(H L)$. Kemudian larutan hasil heap leaching (HL) dicampur dengan bijih laterit yang sudah diseleksi, lalu diproses didalam autoclave dengan teknologi HPAL/PAL. Kegagalan HPAL plant generasi kedua di Australia diduga karena mengolah laterit kadar rendah dengan kandungan silikat tinggi (rata rata $\mathrm{SiO}_{2} \pm 42 \%$ ). Adapun sampai tahun 2015, masih ada proyek-proyek HPAL/PAL plant yang mengalami kesuksesan dan/atau kegagalan seperti yang ditunjukkan olehTabel 5.

Ravensthorpe di Australia menggunakan proses EPAL (Enhance Pressure Acid Leach). Pada proses EPAL, limonit dan saprolit diolah secara bersamaan. Limonit diolah menggunakan proses HPAL/PAL sedangkan saprolit dengan atmospheric leaching ( $A L$ ). Proyekproyek yang mengalami kesuksesan adalah CBNC dan THPAL milik SMM (Sumitomo Metal Mining) Jepang yang beroperasi di Philipina. Sedangkan yang mengalami "kegagalan" karena masih ada masalah pada operasi pabriknya, sehingga kapasitas produksi belum tercapai secara optimal. Masalah tersebut terus dicari jalan keluarnya agar kapasitas produksinya bisa tercapai sesuai dengan yang direncanakan.Telah terbukti sampai 2015, ternyata HPAL plant yang sukses setelah Moa Bay HPAL plant disebabkan karena mengolah limonit dengan kandungan silikat rendah $(\mathrm{Si}<10 \%$ atau $\mathrm{SiO}_{2}<21,43 \%$ ) yang mirip dengan limonit dari Moa Bay Cuba. Atau seperti Minara (dulu Murrin-Murrin) yang mengendapkan silikat 
$\left(\mathrm{SiO}_{2}\right)$ dengan heap leaching $(\mathrm{HL})$. Selanjutnya larutan hasil heap leaching $(H L)$ bersama bijih laterit yang sudah diseleksi, diolah dengan proses HPAL/PAL didalam autoclave. Adapun perbandingan kandungan unsur-unsur bahan baku laterit kadar rendah pada HPAL plant di Cuba, Australia, dan Philipina, dapat dilihat pada Tabel 6 berikut.

Tabel 4. HPAL plant di Cuba, Australia dan Philipina (Dalvi, Bacon, et al., 2004)

\begin{tabular}{|c|c|c|c|c|c|c|}
\hline Operasi & Perusahaan & Negara & $\begin{array}{l}\text { Kapasitas } \\
\text { ton } \mathrm{Ni} / \mathrm{th}\end{array}$ & Produk & $\begin{array}{l}\text { Mulai } \\
\text { Operasi }\end{array}$ & Proses \\
\hline Moa Bay & $\begin{array}{l}\text { Freeport } \\
\text { Pemerintah Cuba } \\
+ \text { Sherrit Gordon } \\
\text { Resolute/Preston }\end{array}$ & Cuba & $\begin{array}{l}25.000 \\
6.000\end{array}$ & $\mathrm{NiS}$ & $\begin{array}{l}1959 \\
2000\end{array}$ & HPAL \\
\hline Bulong & Resources & Australia & 7.000 & $\begin{array}{l}\text { Elektroda } \\
\mathrm{Ni}\end{array}$ & $\begin{array}{l}1998 \\
\text { (tutup 03) }\end{array}$ & HPAL \\
\hline Cawse & Centaur & Australia & 9.000 & $\begin{array}{l}\text { Elektroda } \\
\mathrm{Ni}\end{array}$ & $\begin{array}{l}1998 \\
\text { (tutup 08) }\end{array}$ & HPAL \\
\hline Murrin- Murrin & Anaconda Níkel & Australia & 40.000 & Briket $\mathrm{Ni}$ & 1999 & HPAL \\
\hline Rio Tuba & $\begin{array}{l}\text { Coral Bay } \\
\text { Níkel/Sumitomo }\end{array}$ & Philipina & 10.000 & $\mathrm{NiS}$ & 2004 & HPAL \\
\hline
\end{tabular}

Tabel 5. HPAL/PAL proyek di dunia tahun 2015 (Tsuchida, 2015)

\begin{tabular}{lccccc}
\hline & $\begin{array}{c}\text { Kapasitas } \\
\text { (kT/tahun) }\end{array}$ & Mulai & $\begin{array}{c}\text { Tercapai Disain } \\
\text { kapasitas } \\
\text { (Tahun) }\end{array}$ & $\begin{array}{c}\text { Produksi 2014 } \\
(\mathrm{kT})\end{array}$ & $\begin{array}{c}\text { Indeks biaya } \\
\text { (Biaya PJ/ Ni Ib } \\
\text { pertahun) }\end{array}$ \\
\hline Murrin-Murrin & 45 & 1999 & 2013 & 44,1 & - \\
Ravensthorpe & 45 & 2008 & - & 36,4 & 28,2 \\
Goro & 60 & 2011 & - & 19,8 & 52,8 \\
Ramu & 31 & 2012 & - & 19,9 & 30,6 \\
Ambatovy & 60 & 2012 & 2011 & 37,0 & 52,9 \\
CBNC & 20 & 2009 & 2015 & 24,0 & 12,6 \\
THPAL & 30 & 2013 & & 26,3 & 27,1 \\
\hline
\end{tabular}

Tabel 6. Kandungan unsur-unsur pada laterit kadar rendah untuk bahan baku HPAL plant (Habashi, 1993., Motteram dan Ryan, 1997; Tsuchida,Osaki, et al.,2004)

\begin{tabular}{cccc}
\hline \multirow{2}{*}{ Unsur } & \multicolumn{3}{c}{ \% Berat } \\
\cline { 2 - 4 } & Limonit Moa Bay & $\begin{array}{c}\text { Nontronite Murrin } \\
\text { Murrin }\end{array}$ & Limonit Rio Tuba \\
\hline $\mathrm{Ni}$ & 1,30 & 1,30 & 1,26 \\
$\mathrm{Co}$ & 0,15 & 0,09 & 0,09 \\
$\mathrm{Fe}$ & 48 & 22 & 42,30 \\
$\mathrm{Al}$ & 4,50 & 2,50 & 1,83 \\
$\mathrm{Mg}$ & 1,00 & 4 & 2,21 \\
$\mathrm{SiO}_{2}$ & $\mathbf{3 , 7}$ & $\mathbf{4 2}$ & $\mathbf{1 7 , 4 6}(\mathbf{S i} \pm \mathbf{8 , \mathbf { 1 5 }})$ \\
$\mathrm{Mn}$ & 0,75 & 0,40 & 0,70 \\
$\mathrm{Cr}$ & - & - & 1,89 \\
\hline
\end{tabular}


Akibat dari kegagalan HPAL plant di Australia, otomatis berpengaruh terhadap pasokan nikel dunia dan rencana pembangunan HPAL plant dibeberapa negara terutama dua proyek HPAL plant di Indonesia. Karena 2 (dua) proyek yang ada di Indonesia termasuk proyek strategis untuk memasok kebutuhan nikel dunia. Kedua proyek tersebut ádalah PT Weda Bay Níkel (WBN) Canada di teluk Weda Halmahera dan PT BHP Australia di pulau Gag Papua.

Perkembangan selanjutnya dari tanah air, menurut Website Weda bay nickel ERAMET, bahwa PT Weda Bay Níkel (WBN) Canada yang telah melakukan studi lengkap untuk mengolah laterit kadar rendah teluk Weda Halmahera dengan teknologi berbasis
HPAL/PAL, beralih kepemilikannya ke Eramet Perancis pada Mei 2006. Sedangkan PT BHP Australia mengembalikan ijinnya ke pemerintah Indonesia pada November 2008 (Anonim, 2008). Sampai saat ini (2015), PT WBN Eramet belum merealisasikan proyeknya, bahkan Eramet mempunyai rencana untuk mengolah laterit teluk Weda dengan proses $\mathrm{AL}$ (Atmospheric Leaching). Rencana tersebut dapat dilihat pada Gambar 3.

Kegagalan HPAL plant generasi kedua di Australia dan tertundanya proyek-proyek HPAL plant juga menyebabkan kekurangan pasokan nikel dunia. Sehingga harga nikel dunia naik secara tidak terkontrol, puncak kenaikan harga terjadi pada 2007 seperti yang ditunjukkan oleh Gambar 4.

\section{Rencana Bagan alir proses Weda Bay}

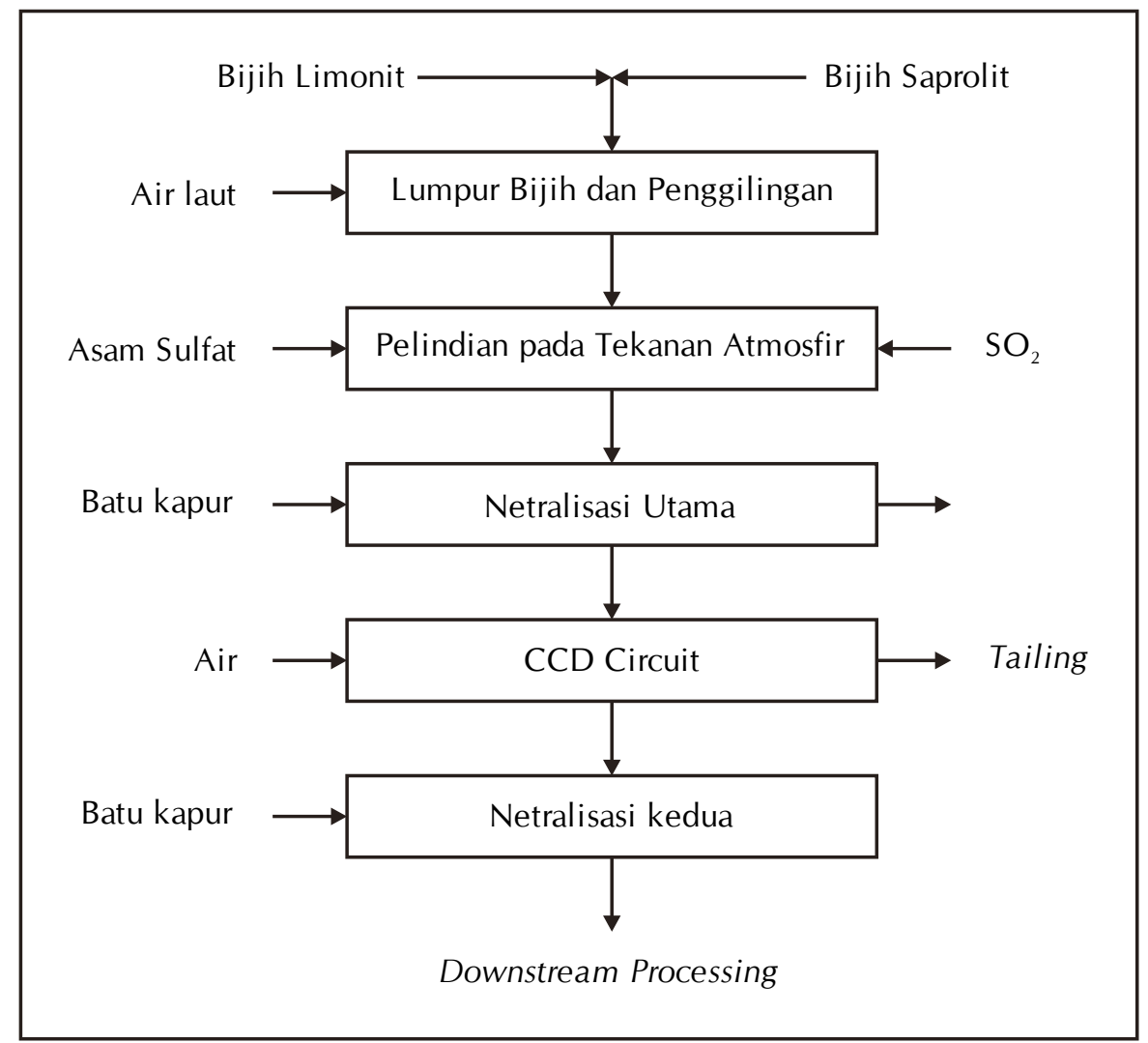

Gambar 3. Rencana bagan alir pengolahanbijih laterit oleh PT Weda Bay Eramet (Taylor, 2013) 


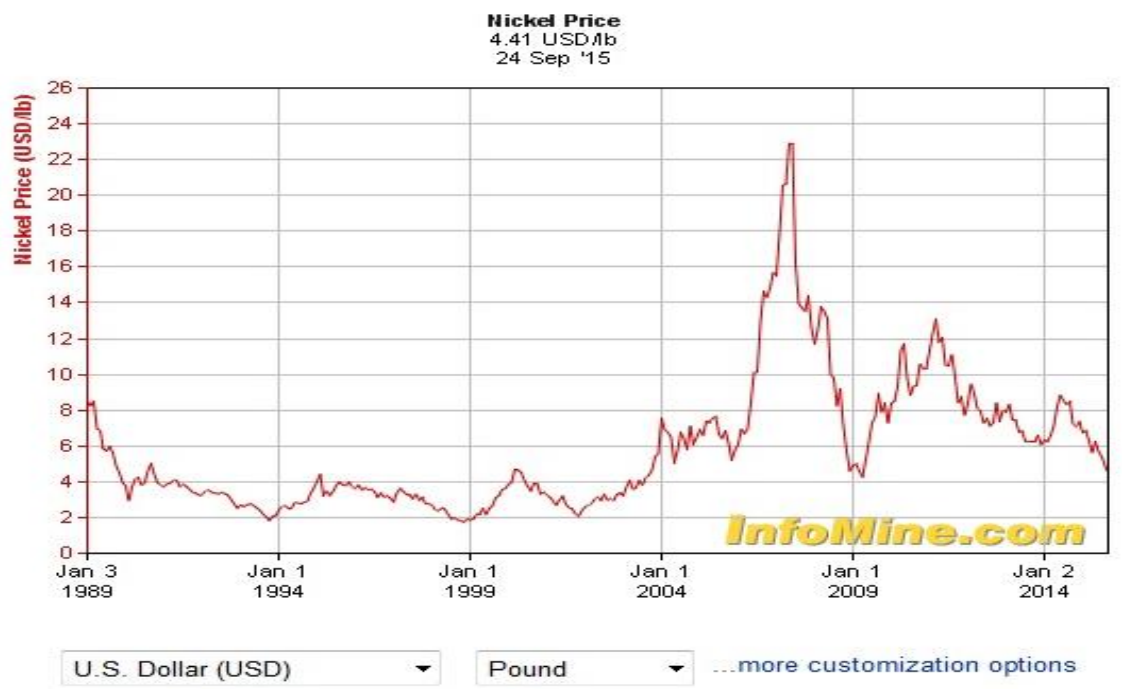

Gambar 4. Harga nikel periode Januari 1989 s/d Januari 2014 (Anonim, 2015)

Pada saat harga nikel di pasar dunia naik secara tidak terkendali terutama pada periode tahun 2005--2008. Pemerintah Tiongkok membuat kebijakan dengan membuat NCPI/NPI dari laterit kadar rendah. Selanjutnya NCPI/NPI digunakan sendiri oleh Tiongkok untuk membuat besi-baja SS 200, SS 300 dan SS 400.

\section{Pembuatan NCPI/NPI (Nickel Contain Pig Iron/ Nickel Pig Iron)}

Prinsip pembuatan NCPI/NPI dari laterit kadar rendah sama seperti pembuatan FeNi. Tiongkok adalah negara pelopor sekaligus pengguna NCPI/NPI untuk pembuatan besibaja. Hal ini berlatar belakang karena Tiongkok sangat membutuhkan besi-baja untuk pembangunan infrastuktur di dalam negerinya sehubungan dengan berlangsungnya Olympiade Beijing 2008, dan Tiongkok sangat membutuhkan besi-baja terutama pada tahun 2004. Dimana untuk membuat besi-baja dibutuhkan nikel terutama FeNi. Melihat kenyataan bahwa harga nikel dunia berfluktuasi dan mahal, seperti yang ditunjukkan pada Gambar 4 diatas. Maka pemerintah Cina membuat kebijakan untuk memproduksi NCPI/NPI dari laterit kadar rendah yang diimpor dari Philipina, Indonesia, dan Kaledonia Baru. $\mathrm{NCPI} / \mathrm{NPI}$ pertama kali diproduksi di Cina pada tahun 2003/2004. Selanjutnya NCPI/NPI digunakan sendiri oleh Tiongkok untuk bahan baku pembuatan besi-baja tipe SS 200, SS 300 dan SS 400. Pada umumnya NCPI/NPI digunakan untuk membuat SS 300, adapun produksi besi-baja terutama SS 300 di Tiongkok, dapat dilihat pada Gambar 5.

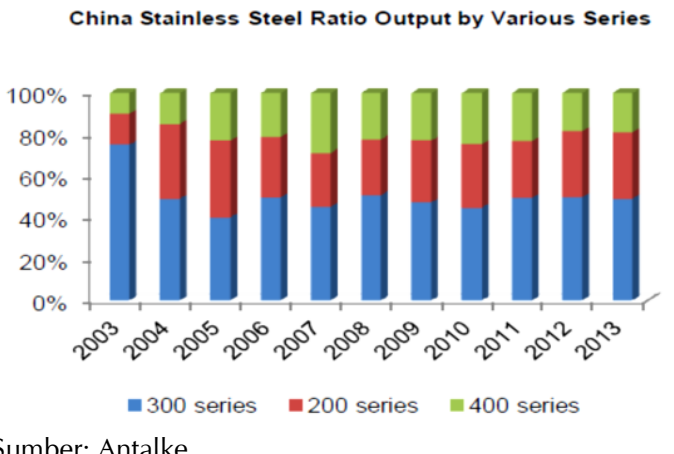

Gambar 5. Produksi besi-baja di Cina sampai tahun 2013 (Anonim 2014)

Gambar 5 dan prediksi 2014 menginformasikan bahwa produksi SS di Cina sampai Oktober 2014 mencapai 1,773 juta ton, turun 1,2 \% setiap bulan (m-o-m). Produksi SS 400 naik 14 $\%$ setiap bulan (m-o-m) mencapai $388 \mathrm{kt}$ atau $22 \%$ produksi nasional. Produksi SS 200 turun $6,9 \%$ setiap bulan (m-o-m) mencapai 568 kt atau $32 \%$ produksi nasional. Produksi SS 300 turun 3,4\% setiap bulan (m-o-m) mencapai 816 kt atau $46 \%$ produksi nasional. 


\section{Undang-Undang Minerba 2009 dan Pengolahan Laterit di Indonesia}

UU Minerba 2009 mengamanatkan bahwa bahan baku mineral harus diolah di tanah air sebelum diekspor, dan ekspor bahan baku mineral diberhentikan mulai 12 Januari 2014. Dengan terbitnya UU tersebut tidak ada masalah untuk saprolit yang memiliki kandungan $\mathrm{Ni} \geq 1,8 \%$ karena sudah ada industri yang siap mengolahnya di Sulawesi Tenggara. Saprolit tersebut diolah menjadi FeNi oleh BUMN PT Aneka Tambang (Antam) di Pomalaa, dan nikel matte oleh PMA PT Vale Indonesia di Sorowako. Sebaliknya, UU Minerba 2009 akan menjadi masalah yang tidak sederhana bagi BUMN PT Antam yang mengekspor bahan baku laterit, dan laterit kadar rendah yang belum diolah di tanah air. Apabila laterit kadar rendah diolah di dalam negeri, ada tiga pilihan teknologi yang tersedia dan sudah komersial yaitu proses Caron, proses HPAL/PAL, dan pembuatan NCPI/NPI. Untuk mengolah laterit kadar rendah melalui jalur proses hidrometalurgi (proses Caron dan proses HPAL/PAL) di tanah air, pemerintah telah memberi ijin pihak asing untuk mengolah laterit pulau Gag Papua dan teluk Weda Halmahera Maluku Utara. PT Pasific Nickel USA pada Februari 1969 mendapat ijin untuk mengolah laterit pulau Gag dengan proses Caron. PT Pasific Nickel USA awalnya akan membangun Caron plant di pulau Gag Papua pada tahun 1974/1975, tetapi akhirnya dengan berat hati membatalkan pembangunan pabriknya di pulau Gag, dan mengembalikan ijin ke pemerintah. Hal ini dilakukan sebagai akibat harga minyak dunia yang melambung tinggi setelah 1973. Sehingga proses Caron ditinggalkan dan pengolahan laterit kadar rendah beralih ke proses HPAL/PAL. Proses HPAL/PAL telah terbukti berhasil di Moa Bay yang diketahui mengkonsumsi energi rendah dengan perolehan (recovery) logam yang tinggi untuk nikel maupun kobal $(\mathrm{Ni}>90 \%$ dan $\mathrm{Co}>90$ $\%)$. Bandingkan dengan perolehan (recovery) logam dari proses Caron yang rendah yaitu untuk $\mathrm{Ni}=75-80 \%$ dan $\mathrm{Co}=35-50 \%$. Selain itu kebutuhan energi proses Caron relatif tinggi karena membutuhkan proses pengeringan dan pemanggangan (lihat Gambar 2).

Untuk mengolah laterit dengan proses HPAL/PAL pemerintah telah mengeluarkan ijin kepada 2 (dua) PMA pada Februari 1998. Dua
PMA tersebut adalah PT BHP Australia untuk mengolah laterit pulau Gag Papua, dan PT Weda Bay Nickel (WBN) Canada untuk mengolah laterit teluk Weda Halmahera Maluku Utara. Perkembangan selanjutnya PT WBN Canada beralih kepemilikan ke Eramet Perancis pada Mei 2006, dan sampai tahun 2015 PT WBN Eramet belum merealisasikan proyeknya. Sedangkan PT BHP Australia mengebalikan ijin pulau Gag Papua ke pemerintah RI pada November 2008. (Anonim, 2008).

Tertundanya pengolahan laterit kadar rendah di tanah air (yang menggunakan proses Caron maupun proses HPAL/PAL oleh PMA), disebabkan oleh faktor ekonomi untuk proses Caron dan teknologi yang "gagal" untuk proses HPAL/PAL. Walaupun proses HPAL/PAL telah sukses secara laboratorium maupun pilot plant untuk mengolah berbagai jenis laterit. Ternyata proses HPAL/PAL gagal saat digunakan pada tiga HPAL plant generasi kedua di Australia, kegagalan tersebut diduga karena mengolah laterit kadar rendah Australia dengan kandungan silikat tinggi (rata rata $\mathrm{SiO}_{2} \pm 42 \%$ ). Hanya Coral Bay HPAL plant generasi ketiga di Rio Tuba Philipina yang sukses. Karena mengolah limonit mirip limonit Moa Bay seperti yang ditunjukkan pada Table 6 di atas, yaitu limonit dengan kandungan silikat rendah ( $\mathrm{Si}<10 \%$ atau $\mathrm{SiO}_{2}<21,43 \%$ ).

Akibat kegagalan HPAL/PAL maka banyak proyek-proyek pengolahan laterit kadar rendah dengan HPAL/PAL maupun EPAL (Enhance Presure Acid Leach) yang berbasis HPAL/PAL ditunda pembangunannya. Kegagalan tiga (3) HPAL plant di Australia membawa pengaruh terhadap pasokan nikel dunia terutama pasokan nikel ke Tiongkok. Karena pasokan nikel dunia berada pada posisi lebih rendah dari yang diproyeksikan. Sehingga harga nikel dunia periode 2003 - 2007, naik secara drastis seperti ditunjukkan oleh Gambar 4. Melihat kenyataan ini maka pemerintah Cina membuat kebijakan untuk memproduksi NCPI/NPI dari laterit kadar rendah yang diimpor dari Philipina, Indonesia, dan New Caledonia. Seluruh produk NCPI/NPI dibeli oleh pemerintah untuk membuat besi-baja tipe SS 200, SS 300, SS 400 dan sebagian besar NCPI/NPI digunakan untuk membuat SS 300. Kenyataan ini, dapat dilihat pada Gambar 5 diatas, dimana saat pemerintah Cina membuat kebijakan, memaksa industri besi-baja di dalam negerinya 
untuk membuat NCPI/NPI. Karena Cina sangat membutuhkan nikel untuk memproduksi besibaja terutama SS guna menunjang pembangunan infrastruktur olimpiade Beijing 2008. Gambaran dari jumlah laterit yang diimpor oleh Tiongkok dalam periode 2005 2011, dapat dilihat pada Gambar 6.

Tiongkok mengimpor laterit dari Philipina terutama untuk laterit yang mengandung $\mathrm{Ni}<$ $1,5 \%$ (limonit), dan dari Indonesia terutama untuk laterit yang mengandung $\mathrm{Ni} \geq 1,5 \%$ (saprolit kadar rendah). Pada 2013, Tiongkok mengimpor laterit dari Indonesia \pm 41 juta ton sedangkan dari Philipina mengimpor \pm 29,6 juta ton. (Jiang, Wang, et al., 2014). Dengan mulai berlakunya UU Minerba yang melarang ekspor bahan baku mineral mulai 2014. Maka Tiongkok yang tidak mempunyai sumber daya alam laterit namun menjadi negara produsen $\mathrm{NPI}$, dengan terpaksa memindahkan pabrik NPI keluar Cina khususnya Indonesia. Selanjutnya pemerintah Indonesia telah memberi ijin investor Cina untuk mengolah laterit kadar rendah terutama di Sulawesi, dan kenyataan tersebut dapat dilihat pada Tabel 7 berikut.

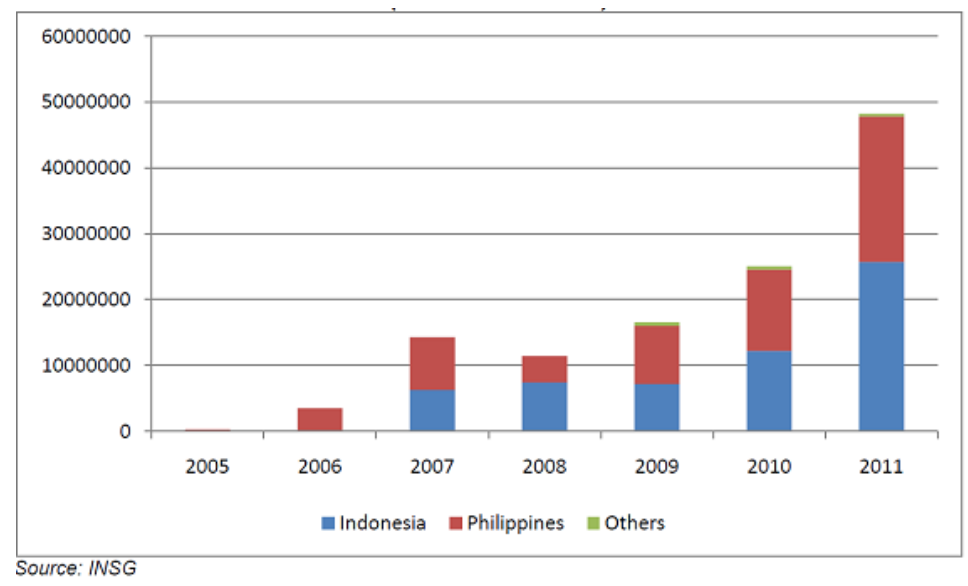

Gambar 6. Impor laterit oleh Cinaperiode 2005 - 2011 (Anonim, 2012).

Tabel 7. Rencana Pengolahan Laterit Di Indonesia Sebagian Besar Untuk Memproduksi NPI (Jansson, 2014)

\begin{tabular}{|c|c|c|c|c|c|}
\hline Perusahaan & Daerah & $\begin{array}{l}\text { Biaya } \\
\text { Modal }\end{array}$ & $\begin{array}{c}\text { Proyeksi } \\
\text { Start }\end{array}$ & $\begin{array}{l}\text { Produksi } \\
\text { (kt/tahun) }\end{array}$ & $\begin{array}{c}\text { Grade } \\
\text { NPI } \\
\text { (kadar } \\
\mathrm{Ni} \text { ) }\end{array}$ \\
\hline PT Antam & Pomalaa & $\$ 573$ & 2014 & 10 & - \\
\hline China Nickel Resource & Kalsel & $\$ 1800$ & 2015 & 60 RKEF & - \\
\hline Tiangshan PT Sulawesi & Sulteng & $\$ 672$ & 2015 & 30 RKEF & 10 \\
\hline PT Maoka/Ningbo Brillmetal & Sultra & $\$ 15$ & 2015 & $18 \mathrm{BF}$ & 10 \\
\hline PT Antam & Halmahera & $\$ 1600$ & 2015 & 27 & \\
\hline Shenwu PT Titan (Tahap I) & Jawa Timur & $\$ 420$ & $2015-2017$ & 35 RKEF & $15 \%$ \\
\hline Ibris Group/TazhouYongzing Alloyed & & $\$ 1800$ & $2015-2017$ & 60 RKEF & $8 \%$ \\
\hline Hanking & Sultra & & 2016 & $4040 \mathrm{BF}$ & \\
\hline Solaway Group & Halmahera & & 2016-2018 & 38 RKEF & \\
\hline PT Maoka/Ningbo Brillmetal & Sultra & & 2017 & $36 \mathrm{BF}$ & \\
\hline Zhensi Group & Maluku & & 2017 & $80 \mathrm{BF}$ & \\
\hline Bosowa & Jane Ponto & $\$ 300$ & 2017 & 10 & \\
\hline PT Vale Indonesia/SMM & Pomalaa & & 2017 & $48 \mathrm{Ni}(\mathrm{OH})_{2}$ & \\
\hline PT Weda Bay Tahap I & & & 2017 & $36 \mathrm{Ni}(\mathrm{OH})_{2}$ & \\
\hline PT Tiga Baji Mining & Sulteng & $\$ 100$ & 2017 & $100 \mathrm{FeNi}$ & \\
\hline Ning Xia Hengshun & & & 2017 & 100 & \\
\hline PT Antam & Sulawesi & & 2018 & $24 \mathrm{NPI}$ & \\
\hline Shenwu PT Titan (Tahap II) & Jawa Timur & $\$ 170$ & $?$ & 81,2 RKEF & $14 \%$ \\
\hline
\end{tabular}

Sumber : Handelsbanken, Blommberg 
- Pada umumnya untuk memproduksi NPI digunakan RKEF (Rotary Kiln Electric Furnace) atau BF (Blast Furnace).

\section{KESIMPULAN DAN SARAN}

Pengalaman pemerintah Tiongkok yang mengeluarkan kebijakan untuk memproduksi $\mathrm{NCPI} / \mathrm{NPI}$ karena harga nikel saat itu berfluktuasi dan mahal, dimana NPI digunakan sebagai pengganti $\mathrm{FeNi}$ untuk pembuatan besi-baja. Kebijakan tersebut mewajibkan seluruh industri metalurginya memproduksi NPI, dan seluruh produk NPI dibeli oleh pemerintah Tiongkok. Pengalaman konsorsium perusahaan Jepang yang dipimpin Sumitomo saat membangun dua HPAL/PAL plant di Philipina, yaitu CBNC (Coral Bay Nickel Corporation) dan THPAL (Taganito HPAL). Belajar dari pengalaman kegagalan maupun keberhasilan CBNC. Sumitomo Metal Mining (SMM) saat membangun THPAL butuh waktu sekitar 15 tahun sejak dari penelitian dasar di laboratorium, pilot plant, hingga membangun HPAL plant. Pembangunan proyek THPAL membutuhkan dana US \$ 1590 juta, lebih mahal US \$ 510 juta dari proyek CBNC. Selanjutnya NiS (nikel sulfida) produk kedua HPAL plant (CBNC dan THPAL) diolah lebih lanjut oleh SMM di Niihama Jepang. Berdasarkan dua contoh (pengalaman Tiongkok dan Jepang) tersebut menunjukkan bahwa agar bisa membangun pabrik pengolahan laterit kadar rendah dibutuhkan teknologi yang sesuai karakteristik bijih, target pasar yang siap untuk membeli produk hasil pengolahan, dan perlu dana besar. Terlihat peran pemerintah Tiongkok yang berupaya agar terpenuhi kebutuhan nikel untuk industri besi-bajanya dengan cara mengeluarkan kebijakan. Demikian juga dengan pemerintah Jepang untuk mendapatkan logam nikel untuk kepentingan nasionalnya, berusaha menguasai teknologi HPAL/PAL agar dapat mengolah limonit menjadi NiS. Untuk Indonesia, terbitnya UU Minerba 2009 yang mewajibkan mineral harus diolah di tanah air menimbulkan masalah yang tidak sederhana. Oleh karena itu, pemanfaatan laterit di Indonesia (khususnya laterit kadar rendah) tentu juga memerlukan keberpihakan pemerintah agar UU Minerba tersebut berdampak positif. Pemerintah melalui Menteri Energi dan Sumerdaya Mineral perlu mengumpulkan para ahli pertambangan terutama dari perguruan tinggi dan instansi riset untuk diminta masukannya. Para ahli tersebut dibayar dan diminta pendapatnya untuk mendapatkan jalan keluar. Selanjutnya masukan dan saran para ahli tersebut dijadikan kebijakan pemerintah.

\section{UCAPAN TERIMA KASIH}

Penulis mengucapkan terima kasih kepada Pusat Penelitian Metalurgi dan Material (P2M2) LIPI. Melalui tematik 2015, P2M2 LIPI membiayai aktivitas pengolahan dan peningkatan nilai tambah mineral nikel. Sehingga dari aktivitas tersebut alhamdulilah dihasilkan tulisan dengan judul diatas. Penulis juga mengucapkan terima kasih kepada Puslitbang TEKMIRA yang menerbitkan tulisan ini. Mudah-mudahan tulisan ini membawa manfaat.

\section{DAFTAR PUSTAKA}

Anonim, 1986. The Cofremmi Acid Leach Process For Laterite Ores, COFREMMI S.A, Compagnie Francaise d'Entreprises minieres, Metallurgi ques et d'Investissements.

Anonim, 1999.PT Aneka Tambang, An Overview September1999. Brosur dariPT Aneka Tambang tentang Pomalaa dan Gebe.

Anonim, 2008. : BHP Writes off Gag Island Laterite Resources.The Australian Business Review November, 14th.

Anonim, 2012. Nickel Ore Shipment To China.INSIGHT, No.16, April. INSG (International Nickel Study Group).

Anonim, 2012.Penanda Tanganan Kontrak PT Pasific Nickel Indonesia.

Anonim, 2014. The Most Essential and Autoritative Source for Chinese Metals Market. No 43. December.Beijing Antaike Information Development CoLtd.

Anonim, 2015, Info Mine, 24 September.

Baillie, M.G. 2002.An Update of The Weda Bay Nickel/Cobalt Laterite Project, Weda Bay Minerals Inc, ALTA.

Butt, C., 2007. Nickel laterite characteristic, classification, and processing option, August. 
Chalkley, M.E. dan Toirac, I.L., 1997. Hydrometallurgy and Refining of Nickel and Cobalt. Proceeding of Nickel-Cobalt 97 International Symposium. Volume 1, August 17-20, Sudbury, Ontario, Canada. p. 341353.

Dalvi, A.D., Bacon, W.G. dan Osborne, R.C.,2004. The Past and The Future of Nickel Laterite, PDAC 2004 International Convention Trade Show \& Investors Exchange, March7 - 10, 2004. INCO Limited, 2060 Flavelle Boulevard, Sheridan Park, Mississauga, Ontario L5K 1Z9, Canada.

Elias, M., 2013.Nickel Laterites in S.E Asia,Geology, Technology and Economics Finding the Balance, in East Asia : Geology, Exploration Technologies and Mines. Principal Consultant CSA Global, Bali,May 27, 2013.

Habashi, F., 1993. Extractive Metallurgy of Copper, Nickel, and Cobalt, Proceeding of the Paul E. Queneau International Symposium 1993.Cuba.

Jiang, K., Wang, H., Li, L.dan Liu, S., 2014. The Process Research And Development For Copper, Nickel And Cobalt In BGRIMM (Beijing General Research Institute Of Mining And Metallurgy). ALTA, Free Paper.

Jansson, M., 2014. From Indonesia to China and Back Again. Commodity Strategy, June 25, Handelsbanken Capital Market.

Lennon, J., 2007. The Chinese Nickel Outlook And The Role of Nickel Pig Iron,Presentation to International Nickel Study Group, Macquarie Research Commodities. May 11, 2007.

Motteram, G.dan Ryan, M., 1997. Hydrometallurgy and Refining of Nickel and Cobalt, Proceeding of Nickel-Cobalt 97 International Symposium-Volume 1, August 17-20, 1997, Sudbury, Ontario, Canada.. p. 391 - 407.

Prado, L.F., 2004. Sixty Years of Caron,Current Assesment, International Laterite Nickel Symposium 2004. Ed. W.P Imrie and D.M.
Lane. TMS (The Minerals, Metals \& Materials Society). March, p. $14-18$.

Rodrigues, F.M., 2013. Investigation Into The Thermal Upgrading Of Nickeliferous Laterite Ores. A thesis submitted to the Robert Buchan Departement of Mining In Corminity with the requirements for The degree of Master of Applied Sciece. Queens University, Kingston, Toronto, Canada.

Taylor, A., 2013. Laterite Still a Frontier of Nickel Process Development. Nickel-Cobalt., Eds. : Thomas Battle, Michael Moats, Violina Cocalia, Harold Oasterhof, Shafiq Alam, Antoine Allanore, Rodney Jones, Nathan Stubina, Corby Anderson, and Shijie Wang.TMS (The Minerals, Metals \& Materials Society).

Tsuchida, N., Osaki, Y., Nakai, O.dan Kobayashi, H., 2004.Development of Process Design For Coral Bay Nickel Project, International Laterite Nickel Symposium . Ed. W.P Imrie and D.M. Lane. TMS (The Minerals, Metals \& Materials Society). March 14 - 18., p. 151 160.

Tsuchida, N. 2015. HPAL in Past, Present, and Future,Nickel - Cobalt - Copper Proceedings. ALTA 2015, Free Papers, Australia.

Wicker, G.R. and Jha, M.C. 1986.Developments in the AMAX-COFREMMI Acid Leach Process for Nickel Laterites, $25^{\text {th }}$ Annual Conference of Metallurgist of CIM, Toronto Canada, August $17-20$.

Wedderburn, B.,2010. Nickel Heap Leaching Study, INSG (International Nickel Study Group), Enviromental \& Economics Session. April 27.

Wiryokusumo, Y., Loebis, A.S., Badrujaman, T.dan Miraza, T., 1997. "Pomalaa Ferronickel Smelting Plant of PT Aneka Tambang", SouthEast Sulawesi Indonesia, Proceedings of The Nickel-Cobalt 97: International SymposiumVolume III, August 17 - 20,Sudbury, Ontario, Canada. 
